\title{
Recruitment of coral-reef fishes to Bermuda: local retention or long-distance transport?
}

\author{
Eric T. Schultz, Robert K. Cowen
}

Marine Sciences Research Center, State University of New York, Stony Brook, New York 11794-5000, USA

\begin{abstract}
The benthic marine fauna of isolated oceanic islands may be self-seeding, or alternatively may be continually supplied with recruits advected from elsewhere by ocean currents. Estimates of the time required for transport of larvae from elsewhere was combined with information on the larval durations of fishes inhabiting the reefs of Bermuda, to test the hypothesis that other populations are sources for recruits to Bermuda. Specifically, we tested the prediction that transport occurs frequently enough to sustain local populations of reef fishes. Transport of larvae was modelled as a 2 -step process in several numerical simulations. The first step of transport was assumed to occur via the Gulf Stream. The second step, in which larvae are transported across the northern Sargasso Sea to Bermuda, was modelled in several different ways, involving either cold-core rings thrown off by the Stream, or mixtures of Gulf Stream and Sargasso water entrained by cold-core rings. Travel distances and speeds were estimated from a variety of sources, focusing on satellite imagery of sea-surface temperature. Pelagic larval durations (PLDs) for reef fish on Bermuda were analyzed from the daily age record in the otoliths of 6 wrasse and 1 parrotfish species. When PLDs were compared with transport times, it was determined that transport events would occur too infrequently to sustain Bermudian populations of reef fishes. The PLDs for most of these species are similar to results obtained elsewhere in their geographic range. It is evident that these populations must be mainly replenished via a pool of larvae that are spawned locally and retained in the vicinity of the Bermuda islands.
\end{abstract}

KEY WORDS: Larvae Advection - Otoliths · Gulf Stream - Sargasso Sea Cold-core rings

\section{INTRODUCTION}

In many demersal marine species, particularly those that are reef-dwellers, juveniles and adults are distributed among spatially isolated habitat patches, which are connected by the flow of dispersing larvae. Typically, the larval period lasts for weeks to months (Thresher \& Brothers 1985, Scheltema 1986, Victor 1986a, Wellington \& Victor 1989), providing ample time for transport away from the reef. Indeed, reef fish larvae can be distributed considerable distances from adult habitat; the larvae of some reef fishes are more likely to be collected offshore rather than nearshore (e.g. labrids; Leis \& Miller 1976). Reef fish larvae in some taxa have specialized morphologies that suggest adaptation to long periods of pelagic life (e.g. the acronurus larvae of acanthurids, or the tholichthys larvae of chaetodontids; Richards \& Lindeman 1987). Similarly derived morphologies are seen in many benthic invertebrate larvae (Scheltema 1986). There is some evidence that long-distance transport can result in successful recruitment, including scattered reports of major recruitment events of reef species to sites with few or no breeding adults (e.g. Lutjeharms \& Heydorn 1981a, b, Pillai et al. 1983). High degrees of genetic similarity across wide regions, even among populations separated by thousands of $\mathrm{km}$ of open water, reflect ongoing gene flow or recent periods of dispersal (Rosenblatt \& Waples 1986, Mitton et al. 1989, Lacson 1992, Hately \& Sleeter in press). The widespread pelagic distributions of the larvae of reef dwellers, their morphological specializations, and the evidence for long-distance transport, signify that at least some species are typically subject to wide dispersal in the larval stage.

The view of reef-fish larvae as dedicated dispersers is far from unanimous, and some research indicates that larvae may often be retained near their natal 
reefs. The larvae of some reef fish taxa are consistently found in highest concentrations nearshore (e.g. Powles 1975, Leis 1982, 1993, Kobayashi 1989, Kingsford et al. 1991, Boehlert et al. 1992). Several comprehensive treatments of the potential mechanisms and implications of larval retention have been published recently (Bakun 1986, Farmer \& Berg 1990). Hydrographic features that could serve to entrap larvae in the vicinity of islands include von Karman vortices and other downstream gyres (Sale 1970, Johannes 1978, Hamner \& Hauri 1981, Lobel \& Robinson 1986. Boehlert et al, 1992), topographically-steered flow (Cowen \& Castro in press), and frontal features (Boden 1952, Kingsford 1990, Kingsford et al. 1991). In some shallow areas, the interaction between tidal currents and longshore currents may drive larvae in orbits that return repeatedly to the home reef, over a time scale comparable to larval durations (Black et al. 1991).

In this paper, we utilize information on larval durations and hydrography to assess the likelihood that reef fish populations are self-seeding on Bermuda, an isolated oceanic island. Potential retention mechanisms are currently being researched vigorously at isolated oceanic islands, such as Barbados (Cowen \& Castro in press) and Johnston Atoll (Boehlert et al. 1992). The rationale is that these sites, because of their position at the head of mean flows (Barbados) or their isolation (Johnston Atoll), are unlikely to import recruits from other reefs; if circulation patterns acting as retention mechanisms exist, oceanic islands are a good place to find and study them, with the ultimate objective of seeking generalizations to other environments (Cowen \& Castro in press). However, the assumption that long-distance transport to isolated oceanic islands is unlikely has never been tested, and that is our present aim.

Bermuda has fully developed coral reefs and a diverse reef fish fauna, with a strong taxonomic affinity to Caribbean assemblages. Based on the similarity of the fauna, there would appear to be some flow of dispersers to Bermuda from the Caribbean, at least over evolutionary time scales. The Gulf Stream (GS), which passes north and west of the islands, most likely provides the first portion of this linkage (Tee-Van 1930). The second leg of the journey, through the northern Sargasso Sea, would involve mesoscale structures such as cold-core eddies or rings (Ring Group 1981), which inject considerable amounts of GS water into the Sargasso Sea (Richardson 1983) and are known to reach the vicinity of Bermuda (Lai \& Richardson 1977, Hogg et al. 1978). Other features that detrain water from the GS into the Sargasso Sea and may be mechanisms for larval transport are referred to collectively as warm outbreaks (Cornillon et al. 1986)
As emphasized by Scheltema (1986), investigation of larval dispersal requires: (1) information on circulation patterns, (2) knowledge of larval durations, and (3) insight into larval behavior, particularly vertical movements. The circulation of the GS and northern Sargasso Sea region has been fairly well characterized, enabling us to construct detailed transport scenarios and estimate the length of time required for the fastest possible transport to Bermuda. We emphasize that we calculate minimum transport times under each set of conditions; in so doing, we are minimizing the chance of falsely rejecting the long-distance transport hypothesis, and placing the burden of proof on the local retention hypothesis. We then present data on the pelagic larval durations (PLD) of reef fish recruiting to Bermuda, and compare these values to previously published data for other populations of these species. A daily age record is present in the earstones (otoliths) of many teleost fishes (Campana \& Neilson 1985), including reef fishes. Fortuitously, a record of the settlement event is characteristically preserved for many of these species, and PLDs can be determined by analyzing the age record of individuals who have already settled (Thresher \& Brothers 1985, Victor 1986a, Wellington \& Victor 1989). Concerning vertical distributions of larvae, few details are needed in our approach. Coral reef fish larvae do exhibit diel vertical movements (Leis 1986), but in most cases are confined to the upper $100 \mathrm{~m}$ of the epipelagic zone (Leis 1991, Cowen $\&$ Castro in press). The maximum current flows for the transport mechanisms we considered occur at these shallow depths, and by assuming that the larvae remain in shallow waters we remain faithful to the testing approach of minimizing potential transport times.

In our analysis of larval durations, we focus on species in the closely-related wrasse family (Labridae) and parrotfish family (Scaridae). In these fishes, daily otolith increments tend to be clear and easily enumerated, facilitating analysis of larval durations. Another important consideration in selecting these fishes for this study is their potential for wide dispersal. Larvae of these families are initially planktonic, hatching from eggs that are broadcast into the water column upon spawning: Perhaps because they are initially incapable of swimming, these larvae are dispersed well offshore (Leis \& Miller 1976, Boekhoedt 1992). Therefore, they would be a likely group to be imported to Bermuda from distant source populations.

The data on larval durations from the otoliths, in conjunction with results from the transport models, permit us to assess whether larvae typically spend sufficient time in the pelagic zone for long-distance transport. The main prediction we test under the long-distance transport hypothesis is that transport events are likely, and that they occur frequently enough to main- 
tain the population. The likelihood of transport events is determined by combining estimates of how long transport will take with information on how long Bermuda recruits actually spent in the larval phase. Also relevant to the transport hypothesis are comparisons of larval durations from the Bermuda recruits with PLDs from other populations: if the time required for transport is longer than the typical PLD for the species, then the recruits that are imported to Bermuda should show prolongation of the larval period. Larvae of some wrasse species have the ability to delay metamorphosis if they do not reach suitable habitat as soon as they are competent to settle (Victor 1986b, Cowen 1991).

\section{MATERIALS AND METHODS}

Transport models. We assumed that the source population producing larvae is at Cape Hatteras, North Carolina, USA. This site was chosen because: (1) it is the closest possible source for imported recruits and (2) many of the reef fish species found in Bermuda have been surveyed in the southeastern USA (Miller \& Richards 1979, Grimes et al. 1982, Lindquist \& Pietrafesa 1989, Parker 1990, G. R. Sedberry, South Carolina Marine Resources Research Inst., pers. comm.). At least some of these populations are probably reproductive: bluehead wrasse Thalassoma bifasciatum off South Carolina (S. Van Sant, South Carolina Wildlife and Marine Resources, pers. comm.) and slippery dick Halichoeres bivittatus off North Carolina (S. Ross, Center for Marine Science, Wilmington, NC, pers. comm.) have been observed spawning in the coastal waters.

To estimate the time required for transport to Bermuda, we constructed 3 numerical simulation models, each representing a possible transport mechanism Results of the models have been evaluated relative to data from several drifter studies (see 'Discussion'). All models transported larvae in 2 legs. The first leg was the same in each case; we assumed that the larvae are initially transported away from Cape Hatteras by the GS, allowing $1 \mathrm{~d}$ for entrainment into the GS. Following the GS portion, we considered 3 possible scenarios for transport of larvae from the GS to Bermuda. The Cold-Core Ring (CCR) model assumed that larvae are present in a CCR when it first develops, and are then carried within that ring until it reaches Bermuda. This model simulated CCR tracks between the GS and Bermuda and determined a travel time to Bermuda for each CCR. Two additional models simulated transport of larvae across the northern Sargasso to Bermuda via GS water entrained around an already formed CCR. Travel time is potentially shorter because such out- breaks of the GS may occur well after the formation of the CCR, and movement of water within the outbreak is related to rotational velocity of the ring rather than the slower translational velocity. The Fixed Position Outbreak model simulated a scenario in which the boundaries of each outbreak are stationary, originating at the GS and terminating at a CCR near Bermuda; circulation within the outbreak transported larvae to Bermuda in a conveyor-belt-like fashion. The Southern Margin Outbreak model simulated movement of the outbreak boundaries, unlike the Fixed Position model. Details of the simulation models follow.

Transport in the GS: To estimate travel times within the GS leg, we gathered information on GS path distances and water speeds. We assumed that larvae travelled at a fixed, peak speed within the GS of $160 \mathrm{~cm} \mathrm{~s}^{-1}$, which is the highest sustained downstream speed at Cape Hatteras (Manning \& Watts 1989). Transport distances along the GS tend to vary because of meanders in the stream's path. To collect information on GS path distances, 18 plots from AVHRR imagery of sea-surface temperature (SST; Ocean Products Center, NOAA) were digitized. The dates analyzed were no less than 1 mo apart, from April to June 1987 to 1990, and April to August 1991. Because of interest in transport times from the Caribbean, we also analyzed SST charts for down-current distances between Cape Hatteras and $25^{\circ} \mathrm{N}$ latitude, where the Florida Current draws water between the Bahamas and Florida and advects it north.

Transport time in the GS leg of each simulation varied, despite the fixed velocities. One reason for this variability was that the longitude at which larvae left the GS and entered the Sargasso Sea (detrainment from the GS) varied from event to event in each model. The other source of variability was GS meanders: these were included in the models by varying GS transport distance, once the longitude of detrainment had been specified for the event. These randomizations of GS transport distance used the measurements of average distance and distance variance outlined above. Travel time was determined by dividing the transport distance in the GS by the fixed velocity.

The latitude of detrainment from the GS also varied randomly from event to event in each model, which was important because of resulting variability in the transport distance within the Sargasso Sea. Variability in position of the GS's landward surface edge (GSLSE) were presented in Auer's (1987) 5 yr survey of the GS and its associated rings. We utilized his information on changes in the average N-S position of the GS by measuring means and standard deviations at each degree longitude (Fig. 3 in Auer 1987), and adding $100 \mathrm{~km}$ (the average width of the GS; Watts 1983) to get the mean position of the GS southern edge. 
Cold-core ring model (CCR): For parameterizing our CCR model, we used Auer's (1987) 5 yr dataset of cold-core ring activity, particularly his information on translational velocities and course changes. Auer (1987) reported translational velocities in 2 components (mean $\mathrm{N}$-S movement $v=0.6 \mathrm{~km} \mathrm{~S} \mathrm{~d}^{-1}, \mathrm{SD}=6.3$; mean $\mathrm{E}-\mathrm{W}$ movement $u=0.7 \mathrm{~km} \mathrm{~W} \mathrm{~d}^{-1}, \mathrm{SD}=5.9$ ). We assumed that these velocities were normally distributed, and independent of each other. We estimated the per-kilometer likelihood of changing course by measuring the distance covered, and the number of turns, in 31 plotted ring tracks (Fig. 11 in Auer 1987).

The simulation generated variability in CCR tracks and transport times by randomizing translational velocity, course changes, and CCR detrainment from the GS. The program flow, which was incremented in time units of $1 \mathrm{~d}$, is illustrated in Fig. 1. Only CCRs that move between the GS and Bermuda are of interest; the number of uninformative ring tracks was reduced in the model by initiating CCRs at Bermuda and running their courses backwards. Course headings and speeds were set by randomly sampling for $u$ and $v$ [using Auer's (1987) parameters listed above], and were run backwards by rotating the course $180^{\circ}$. If the ring was

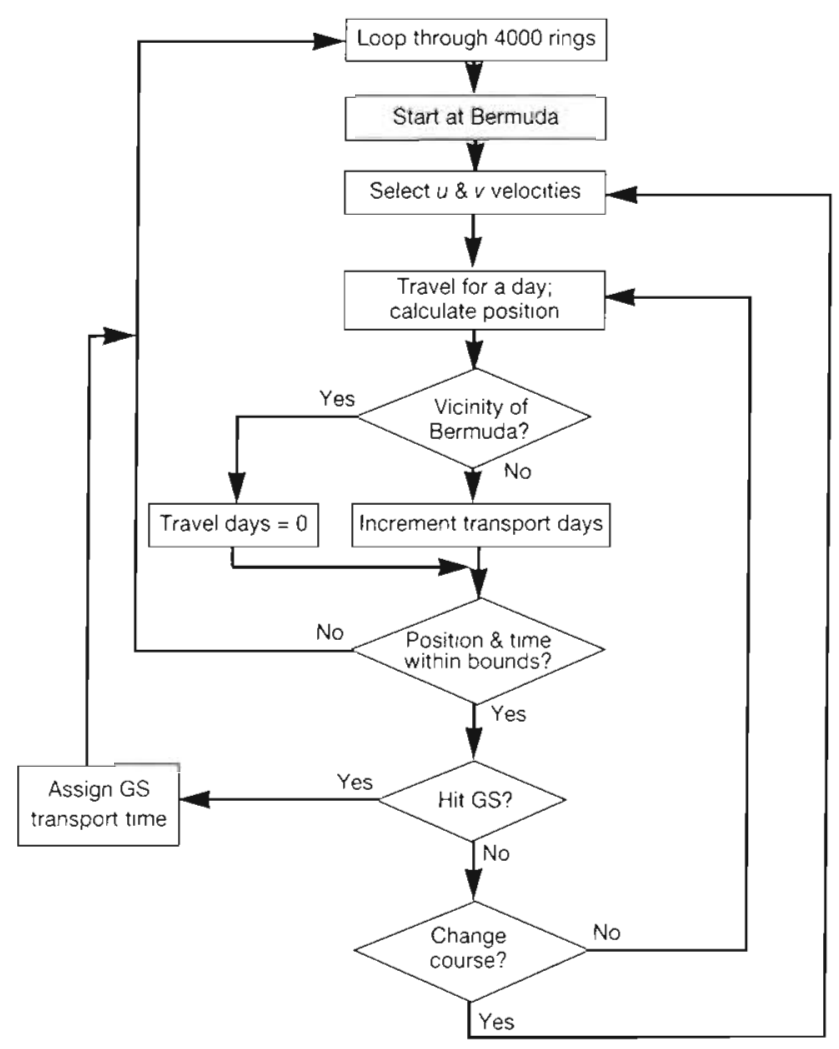

Fig. 1. Flow chart of the cold-core ring (CCR) simulation model of transport times. See text for details in the vicinity of Bermuda $<50 \mathrm{~km}$, value chosen arbitrarily), the travel time clock was set to zero days, so that all travel times would reflect the number of days since the ring was last near the islands. If the CCR traveled west of $75^{\circ} \mathrm{W}$ or east of $30^{\circ} \mathrm{W}$, it was terminated and discarded. The travel times of 4000 rings that made the transit between Bermuda and the GS were accumulated for analysis.

Outbreak model 1: fixed position: GS water also enters the Sargasso Sea in filaments of mixed GS/ Sargasso water that is usually entrained around one or more cold-core rings (Fig. 2). These features have some similarities to phenomena dubbed 'warm outbreaks' (Cornillon et al. 1986), and will be referred to accordingly. Outbreaks have been used as surface CCR signatures when interpreting AVHRR imagery (Auer 1987), because the colder ring cores sink out of sight some time after detrainment from the GS. Outbreaks cover a substantial portion of the surface water in the northern Sargasso Sea (Fig. 2), and are a prominent feature of sea-surface temperature charts (Ocean Products Center, NOAA). We relied on the charts for information as to the configurations and behavior of these water masses.

In the first model of transport within outbreaks, we assumed that the position of the outbreak is fixed, with an origin at the GS and a southern limit at Bermuda. To parameterize this model, we measured several features of outbreaks found on a series of SST charts. The charts used were from the same time intervals listed above, and measurements were taken no less than 1 mo apart. All outbreaks present in a chart were measured (average of 2.1 outbreaks on a given date, $n=30$ outbreaks). The variables measured were: (1) the distance covered by a line through the center of the filament, from the origin to its southernmost reach; (2) the longitudes of the beginning and end of this line, thus providing an E-W extent; and (3) the latitudes of the beginning and end of this line, thus providing a N-S extent.

Another parameter needed in this model was water speed within the fixed boundaries of the outbreak. Assuming that flow is geostrophic, one can then estimate speed in the outbreak (as relative speed, $V_{2}-V_{1}$ ) using the thermal wind equation (Gill 1982, Pond \& Pickard 1983):

$$
\begin{gathered}
\left(V_{2}-V_{1}\right)=g^{\prime} f^{-1} \delta h / \delta X \\
g^{\prime}=g \Delta \rho / \rho, \quad f=2 \Omega \sin (\Phi)
\end{gathered}
$$

where $g=$ gravitational constant, $f=$ Coriolis parameter, $\rho=$ density, $\Omega$ = angular momentum of Earth's rotation, and $\Phi=$ latitude. The slope of the front, $\delta h / \delta X$, was measured from a bathythermograph of entrained water (Fig. $1 \mathrm{~b}$ in Richardson 1980). The change in density across the front, $\Delta \rho$, was approximated as $0.25 \Delta T$, where $\Delta T$ averages 2 over the sum- 

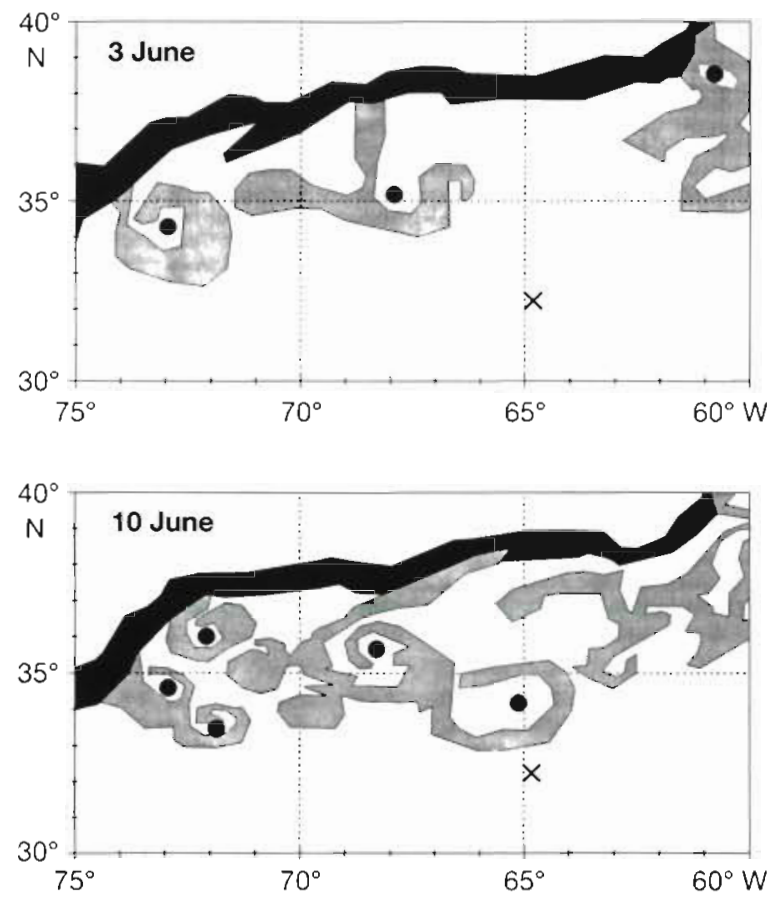

Fig. 2. A portion of the Gulf Stream (GS, dark shading) and northern Sargasso Sea, showing changes in a single week in summer 1991 The data were taken from charts of SST images (Ocean Products Center, NOAA); the northern edge of the GS is simplified, and no data north of the GS are plotted. Light shading: bodies that are mixtures of GS and northern Sargasso Sea water. (1) Cold-core eddies indıcated in the charts; $(\times)$ Bermuda

mer months (entrained water $2^{\circ} \mathrm{C}$ warmer than the Sargasso Sea). Salinity differences across the front are expected to be small. We then assumed that $V_{1}$ (ambient speed in the Sargasso Sea) was 0, for an estimate of speed within the outbreaks.

In the model, detrainment of the outbreak from the GS, and transport distance from the point of detrainment to Bermuda, varied randomly from event to event. Observed ranges for variables measured from charts of outbreaks listed above were used in these randomizations. The water speed estimate determined from the thermal wind equation was multiplied by the transport distance for transport time within the outbreak, and this was added to a GS transport time for total time from Cape Hatteras. The results for 2000 fixed outbreaks were accumulated for analysis.

Outbreak model 2: southern margin movement: Seasurface temperature charts suggest that the mixed Sargasso/GS water masses are dynamic, with changes in shape, translational movements, and sudden entrainments around features such as CCRs (Fig. 2). To summarize this behavior, we measured the southernmost limit of all outbreaks observed in the northern Sar- gasso, in weekly charts from 9 April to 4 June 1990 and 8 April to 29 July 1991 . A total of 117 charted positions were recorded, and daily velocity estimates for the movements of the southernmost limits of the outbreaks were calculated from these data.

The simulation model was structured similarly to the CCR model (see Fig. 1). Bermuda was represented as the origin, and the outbreak margin moved 'backwards' from that point. The travel times of 4000 outbreaks that completed the transit between the GS and Bermuda were accumulated for analysis.

Larval durations and settlement dates. Collections made from 14 to 22 September 1991 around the Bermuda platform yielded 10 species of wrasse (Labridae) and parrotfish (Scaridae), for a total of 338 individuals. Specimens were collected by SCUBA divers, using hand nets and quinaldine, a fish anaesthetic. One species was represented by only one individual in the collection, and specimens of several other species were older individuals in which determination of larval durations is difficult. Therefore we present data on only 7 species. Immediately after capture, the fish were preserved in $95 \%$ ethanol.

Lapilli and sagittae were extracted and examined following standard techniques (Stevenson \& Campana 1992). We estimated larval durations by performing replicate counts of the daily otolith increments from the otolith center to the settlement mark. Following Victor (1986a), we added $2 \mathrm{~d}$ for the period before the otoliths form. A total of 1043 otolith counts were recorded, for an average number of replicate counts per fish of $3.5(\mathrm{SD}=1.1)$. We used variability among replicate counts to assess the reliability of age estimates, quantifying differences between sagitta and lapillus counts, standard deviations of replicate counts, and variance/mean relationships. In a small minority of replicate counts $(n=38)$, aberrant counts could be traced to identifiable errors in interpretation, and these counts were deleted from the analysis

We also determined the date of settlement, in order to assess whether all of our specimens were arriving in single episodes of recruitment. Settlement date was estimated by counting the number of increments after the settlement mark to the edge of the otolith, and back-dating from the date of capture. This is actually the date of 'emergence' which follows settlement, after a short period (about $5 \mathrm{~d}$ in some species, apparently absent in others) in which otolith increments tend to be less distinct and harder to enumerate.

Estimation of transport frequency. The estimates of larval duration were then combined with the model predictions of transport time in order to determine the likelihood of long-distance transport. The estimate of likelihood is expressed as the expected 'recurrence interval' $\left(I_{t}\right)$ between transport events (in years) that 
bring larvae to Bermuda in a given number of days or less. The expression for this interval is

$$
\begin{aligned}
& I_{t}=\left(F P_{t}\right)^{-1}, \\
& P_{t}=\sum_{x=0}^{t} P_{x}
\end{aligned}
$$

where $F=$ expected frequency of CCR visitation to Bermuda $\left(\mathrm{yr}^{-1}\right)$, and $P_{x}=$ the probability that an event transports larvae in $x$ days. The parameter $F$ can be used for both the CCR model and the outbreak model, because outbreaks are presumed to be associated with CCRs. Based on observations by Hogg et al. (1978), and the sea-surface temperature charts listed previously, we used a value for $F=4$ per year.

\section{RESULTS}

\section{Gulf Stream transport}

Measurements of SST charts indicated that cumulative travel distances between Cape Hatteras and points east increased at a roughly linear rate, at $549 \mathrm{~km}$ for every $5^{\circ}$ of longitude. The variability of cumulative distance increases sharply as a result of meandering.

Because the Caribbean is also one possible source for larvae transported to Bermuda, we obtained an estimate of travel times for the portion of the GS between southern Florida across from the Bahamas $\left(25^{\circ} \mathrm{N}\right)$, and Cape Hatteras $\left(35^{\circ} \mathrm{N}\right)$. The average total distance of this leg is $1213 \mathrm{~km}$, and because the flow of the GS is relatively direct and meander-free, there is little variability in this distance $(S D=45)$. Maximum downstream speeds for the stretch between Florida and Cape Hatteras run from 165 to $195 \mathrm{~cm} \mathrm{~s}^{-1}$ (Leaman et al. 1989). We estimate that this leg of the journey should take $7 \mathrm{~d}$.

\section{CCR model}

The distribution of ring travel times in the model was skewed towards longer transport times (Fig. 3A), reflecting the circuitous routes many of the rings took between the GS and Bermuda. The average travel time for this leg was $178 \mathrm{~d}(\mathrm{SD}=82)$, but the median travel time was $171 \mathrm{~d}$. Relative to the CCR leg of the journey, the GS portion of the trip from Cape Hatteras was rapid and there was comparatively little variation in travel times (mean $=7 \mathrm{~d}, \mathrm{SD}=2$ ). Minimum total trip time (GS and CCR legs) was $36 \mathrm{~d}$ (Fig. 3), and the average total trip time was $185 \mathrm{~d}(\mathrm{SD}=82)$.

Ring course changes had a pronounced effect on travel time. When course changes were eliminated from the simulation of ring behavior, CCR transit between Bermuda and the GS took much less time (average $=130 \mathrm{~d}, \mathrm{SD}=75$ )

\section{Outbreak model 1: fixed position}

To estimate the speed of water flow within the outbreak, we measured the slope of the thermal front in an outbreak at the $20^{\circ}$ isotherm (plotted in Richardson 1980 ). The slope at this front was 0.005 , yielding a value of $29 \mathrm{~cm} \mathrm{~s}^{-1}$ for the relative velocity inside outbreaks. The average travel time in the outbreaks was $31.4 \mathrm{~d}(\mathrm{SD}=6.1)$. Total travel times from Cape Hatteras ranged from 20 to $60 \mathrm{~d}$ (Fig. 3B), with an average of $39.5 \mathrm{~d}(\mathrm{SD}=6.5)$.

\section{Outbreak model 2: southern margin movement}

The transport times yielded by the southern margin model tend to be longer than the fixed position outbreak model's but shorter than the cold-core ring model (Fig. 3C). The average transport time was $102 \mathrm{~d}(\mathrm{SD}=56.7)$. Although the mean transport time is longer in the southern margin model than the fixed position model, the southern margin model also yields
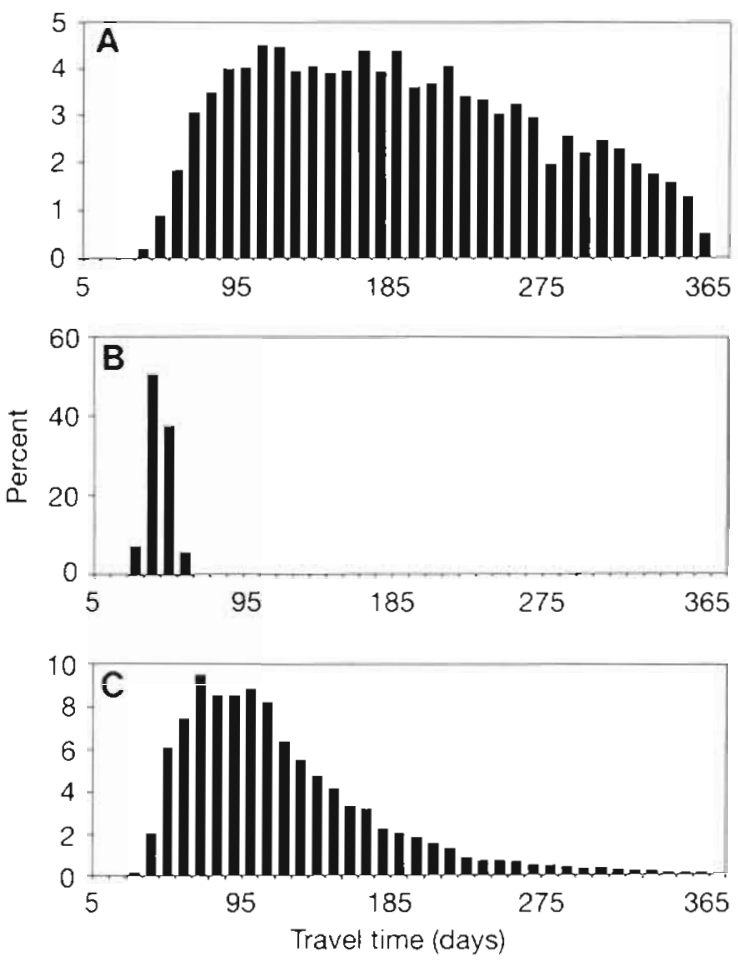

Fig. 3. Output from 3 simulation models of transport, as histograms of transport times between Cape Hatteras and Bermuda. (A) CCR model, $n=4000$; (B) fixed outbreak model, $\mathrm{n}=2000$; (C) southern outbreak margin model, $\mathrm{n}=4000$ 
Table 1. Replicability of otolith counts of larval duration for 7 labroid species captured in Bermuda. Sagitta - lapillus: difference of sagitta and lapillus counts; replicability: average difference among counts for each fish (sagitta only if there is a difference between otoliths); CV vs mean: relationship between coefficient of variation and average count for each fish

\begin{tabular}{|c|c|c|c|c|c|c|c|c|}
\hline & \multirow[t]{2}{*}{$\mathrm{n}$} & \multicolumn{3}{|c|}{ Sagitta - lapillus } & \multicolumn{2}{|c|}{ Replicability } & \multicolumn{2}{|c|}{ CV vs mean } \\
\hline & & Mean & $\mathrm{SE}$ & $\mathrm{p}$ & $\mathrm{SD}$ & $\mathrm{CV}$ & $\mathrm{R}$ & $\mathrm{p}$ \\
\hline Bodianus rufus & 28 & 2.7 & 0.30 & $<0.0001$ & 0.96 & 3.0 & -0.032 & 0.87 \\
\hline Halichoeres bivittatus & 57 & 0.52 & 0.36 & 0.15 & 2.1 & 9.0 & 0.087 & 0.52 \\
\hline H. garnoti & 50 & 0.40 & 0.34 & 0.24 & 1.7 & 7.6 & 0.26 & 0.06 \\
\hline H. maculipinna & 33 & 2.5 & 0.29 & $<0.0001$ & 1.7 & 5.5 & -0.0004 & 1 \\
\hline H. radiatus & 6 & -0.30 & 0.81 & 0.73 & 2.0 & 8.4 & 0.20 & 0.71 \\
\hline Scarus taeniopterus & 70 & 8.2 & 0.52 & $<0.0001$ & 1.2 & 4.2 & -0.15 & 0.22 \\
\hline Thalassoma bifasciatum & $47^{\circ}$ & 3.1 & 1.2 & 0.02 & 2.1 & 3.7 & 0.32 & 0.04 \\
\hline
\end{tabular}

shorter minimum travel times. As in the CCR model, the distribution of travel times is skewed towards longer times.

\section{Larval durations and settlement dates}

The appearance of otoliths varied considerably among and within species. Highly replicable counts [low coefficient of variation (CV), e.g. Bodianus rufus: Table 1 l indicate that daily increments were clear and there were no other interpretation problems. Counts for many of the Halichoeres species were less replicable (higher CV, e.g. H. bivittatus; Table 1). The sources of error contributing to variability in counts were most often subdaily increments, although the otolith center was also sometimes difficult to evaluate, because cracks obscured the increments in some cases. In one species, Thalassoma bifasciatum, there was a relationship between count CV and mean count (Table 1). The increase in CVs with mean counts in this species was due to difficulties interpreting increments near the end of the larval period in some individuals. There were considerable differences between sagitta and lapillus counts in some species (e.g. Scarus taeniopterus); when a significant difference was observed, the sagitta always had a higher mean count than the lapillus (Table 1), possibly reflecting earlier sagittal formation in the larva (Victor 1986a).

In 5 of the 7 species, the distribution of PLDs is positively skewed, meaning that variability in PLD is more confined below the mean than above the mean (Table 2). The amount of variation among individuals (as a proportion of the mean) is roughly the same from species to species (CV among individuals $=\mathrm{SD} /$ mean for species, ranging from $7.9 \%$ for Halichoeres radiatus to $18.9 \%$ for Thalassoma bifasciatum)

Bermuda PLDs were not consistently higher than previously observed values for these species. The PLDs for Bermuda specimens were different in several species from those of southern Caribbean populations (Table 2; cf. Victor 1986a). In one species, Bodianus rufus, the Bermuda values were $25 \%$ less than Victor's values for Panama specimens. B. rufus otoliths are clear and highly replicable, therefore it is unlikely that the large difference for this species can be attributed to

Table 2. Pelagic larval durations for 7 labroid species captured in Bermuda, with results from Victor's (1986a) analysis of samples from the Golfo de San Blas, Panama, for comparison (wrasse species only), and significance of the difference between the samples (2-tailed $t$-test). Summary statistics for the Bermuda samples include skewness; sample sizes are listed in Table 1. For the Panama collections, $n=10$ for all species, except for Thalassoma bifasciatum $(n=1172)$. Variances for the 2 samples were equal except for T. bifasciatum

\begin{tabular}{|c|c|c|c|c|c|c|}
\hline & \multicolumn{3}{|c|}{ Bermuda } & \multicolumn{2}{|c|}{ Panama } & \multirow[t]{2}{*}{$\mathrm{p}$} \\
\hline & Mean & Skewness & SD & Mean & $\mathrm{SD}$ & \\
\hline Bodianus rutus & 32.0 & 0.92 & 3.4 & 41.6 & 6.5 & $<0.001$ \\
\hline Halichoeres bivittatus & 23.5 & 0.73 & 2.3 & 24.1 & 1.5 & $>0.4$ \\
\hline H. garnoti & 22.0 & 0.20 & 1.8 & 25.9 & 2.0 & $<0.001$ \\
\hline H. maculipinna & 30.5 & -0.058 & 3.1 & 25.8 & 2.6 & $<0.001$ \\
\hline H. radiatus & 24.0 & 0.90 & 1.9 & 24.9 & 2.6 & $>0.5$ \\
\hline Scarus taeniopterus & 28.2 & -0.34 & 4.7 & - & - & \\
\hline Thalassoma bifasciatum & 55.0 & 0.38 & 10.4 & 49.3 & 5.5 & $<0.001$ \\
\hline
\end{tabular}




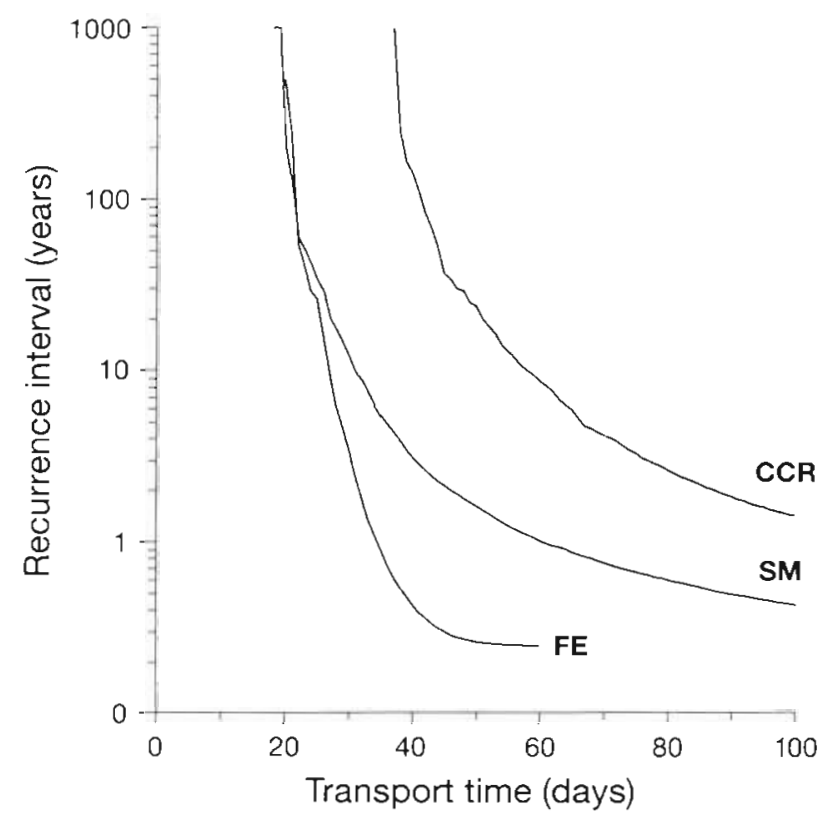

Fig. 4. Recurrence intervals versus transport times in the 3 simulation models. CCR: cold-core ring model; FE: fixed outbreak model; SM: outbreak southern margin movement model

reader differences in interpretation. All other differences were $15 \%$ or less.

Most of the individuals we sampled had recently recruited to Bermuda reefs. The majority of specimens recruited in August, except for our sample of Thalassoma bifasciatum which included recruits throughout the summer and several larger individuals that may have recruited late in 1990 (the settlement date determinations are considered tentative for these older individuals). The individuals we sampled did not arrive in a single episode; the SD of settlement date for all species but $T$. bifasciatum was 7 to 12 .

\section{Transport recurrence interval}

The transport time distributions from the simulation models (Fig. 3A, B, C) can be converted into recurrence interval estimates, indicating the frequency with which such transport events should occur (Fig. 4). The interval estimates from the 2 outbreak models agree closely at shorter transport times, but over much of the range of transport times there is an order of magnitude difference in interval estimates among the 3 models. Combining these estimates with the PLD data (Table 2) permitted us to calculate the average amount of time that would elapse between transport events bringing larvae of each species. We calculated the recurrence interval using the mean PLD for each species, and the maximum and minimum PLDs (Table 3 ). The recurrence interval is inversely related to the PLD, so the maximum PLD yields a minimum recurrence interval. For PLDs that were shorter than any transport event observed in the simulation, the recurrence interval is undefined.

Most PLDs were too short to define a recurrence interval in the CCR model (Table 3). Intervals could be estimated for the species with the longest PLD, Thalassoma bifasciatum; the minimum interval (at the maximum PLD) was roughly 3 yr. Minimum intervals for all other species were more than $100 \mathrm{yr}$.

The outbreak modeis generated many transport events consistent with observed PLDs, and therefore intervals could be estimated for all species. The fixed position model tended to yield shorter interval estimates. For Thalassoma bifasciatum, the intervals at the mean PLD were slightly more than 3 mo (in the fixed position model) or $1 \mathrm{yr}$ (in the southern margin model). Other species for which the intervals at average PLDs were less than 10 yr were Bodianus rufus, Halichoeres maculipinna, Scarus taeniopterus, and (in the fixed position model) H. radiatus.

\section{Drifter tracks}

We evaluated the behavior of a number of satellitetracked drifters that became detrained from the GS into the Sargasso Sea. As part of a study on the effects of deep ocean dumping, 66 surface-layer drifters (drogues centered at $10 \mathrm{~m}$ depth) were released into slope waters of the middle Atlantic Bight (EPA 1993). Without exception, these drifters were eventually entrained into the GS and carried east, in the fast waters of the GSLSE; 6 of these drifters were detrained from the GS in the Sargasso Sea, east of $55^{\circ} \mathrm{W}$ longitude (Fig. 5). Another drifter that had been deployed in a survey of CCR behavior (originally tethered to a $200 \mathrm{~m}$ drogue, but drogue was probably lost shortly after deployment) was entrained into the GS from the Sargasso Sea, south of Cape Hatteras (Richardson et al. 1979). This drifter moved along the GS well to the south of the average position of the GSLSE, was detrained back into the Sargasso Sea somewhere between $70^{\circ} \mathrm{W}$ and $65^{\circ} \mathrm{W}$ longitude, and was recovered fairly close to Bermuda (Fig. 5). The courses taken by these drifters fall into 2 types: the drifters that entrained into the GS from the north moved far to the east, while the drifter that entrained from the Sargasso Sea moved along the GS a relatively short distance before detrainment.

The drifters in these 2 types also translated at different rates in the GS. Those entraining from the north moved faster than $100 \mathrm{~cm} \mathrm{~s}^{-1}$, while the drifter entering the GS from the other side moved much more slowly. Regarding the rate of movement in the Sargasso Sea, 
Table 3. Recurrence intervals (in yr) between long-distance transport events for Bermuda labroids in 3 larval transport simulations. Interval estimates are reported at the mean PLD for each species, and at the observed limits of the range of PLDs. In some cases, no transport events consistent with the PLD value were generated by the simulation model, and a recurrence interval could not be estimated; where possible, the closest value that could be estimated is reported

\begin{tabular}{|lcccccc|} 
& \multicolumn{2}{c}{ Ring model } & \multicolumn{2}{c}{ Fixed position } & \multicolumn{2}{c}{$\begin{array}{c}\text { Southern margin } \\
\text { Range }\end{array}$} \\
& Mean PLD & Range & Mean PLD & Range & Mean PLD \\
\hline Bodianus rufus & $>1000$ & $140->1000$ & 1.9 & $0.4-6.3$ & 8.8 & $3.1-16$ \\
Halichoeres bivittatus & $>1000$ & - & 29 & $1.9->500$ & 42 & $8.8-200$ \\
H. garnoti & $>1000$ & - & 56 & $16->500$ & 59 & $29-1000$ \\
H. maculipinna & $>1000$ & $1000->1000$ & 2.5 & $0.6-42$ & 9.7 & $4.3-50$ \\
H. radiatus & $>1000$ & - & 29 & $9.6-56$ & 42 & $20-58$ \\
Scanus taeniopterus & $>1000$ & $170->1000$ & 6.3 & $0.5->500$ & 17 & $3.4->1000$ \\
Thalassoma bifasciatum & 12 & $3.1-170$ & 0.3 & $<0.3-0.5$ & 1.2 & $0.6-3.4$ \\
\end{tabular}

there was some overlap in the speeds between the 2 types: overall, average speeds ranged from 32 to $91 \mathrm{~cm} \mathrm{~s}^{-1}$. The number of days that each drifter was tracked, from entrainment in the GS to the last fixes in the Sargasso Sea, represents the lower bound on the amount of time the drifter would have taken for the trip from Cape Hatteras to Bermuda (all but one drifter in this set entrained into the GS near Cape Hatteras). These transport times ranged from 33 to $97 \mathrm{~d}$.

\section{DISCUSSION}

\section{Long-distance transport versus local retention}

The results presented in this paper suggest that transport of coral-reef fish larvae to Bermuda from dis-

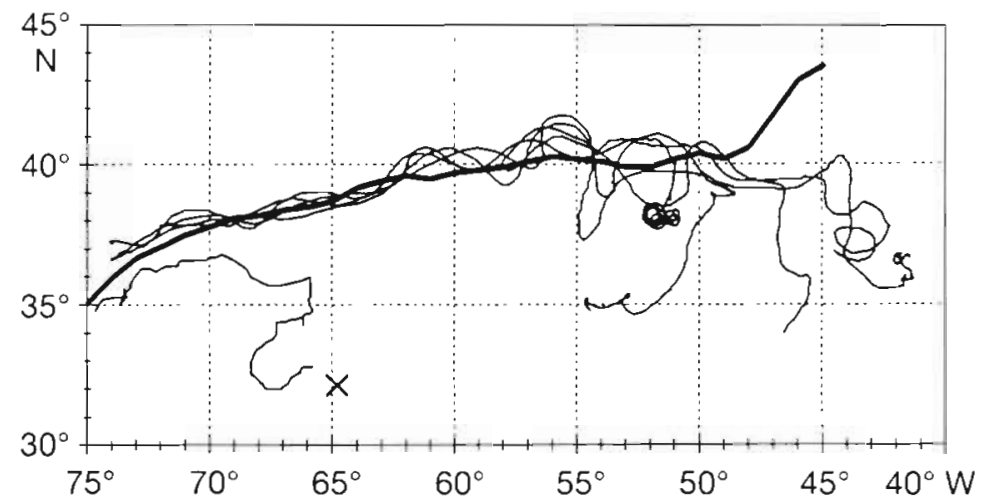

Fig. 5. Drifter tracks for surface-layer drifters entrained in the Gulf Stream (GS) and detrained into the Sargasso Sea; all courses begin to the west and end to the east. Each starting point displayed is where the drifter entrained into the GS (or where the drifter passed Cape Hatteras in the GS), not the point of drifter release. Two drifters entrained into the GS at the same time and were detrained into the same CCR, as indicated by their closed gyral movements; their GS and Sargasso Sea tracks were virtually identical, and only 1 of these tracks is displayed. The heavy line indicates the average position of the landward surface edge of the GS according to Auer (1987). ( $\times$ ) Bermuda tant source populations is a rare event for most species. The simulation models of larval transport were constructed and parameterized in such a way as to minimize larval transport times, while remaining consistent with current knowledge of GS and Sargasso Sea circulation patterns. Despite this bias, most transport events took a long time relative to observed PLDs of Bermudian labroid fishes. Although transport events bringing water rapidly enough to carry viable larvae (feasible transport events) do occur, they are infrequent. We base this conclusion on our estimates of recurrence interval, the average number of years between events that succeed in reaching Bermuda within the time limits of the observed larval durations. These calculations indicate that more than $2 \mathrm{yr}$ will pass between potential recruitments of long-distance larvae, except in the case of Thalassoma bifasciatum.

How frequently must recruitment occur to sustain a local population? The estimates of recurrence interval will be most meaningful when combined with demographic information for these species: even if transport events are rare, a species will persist if the adults are long-lived (Cowen 1985, Warner \& Chesson 1985). Unfortunately, only scant information is available on the mortality rates and longevities of reef fishes, and it is difficult at this time to precisely indicate how long it would take a local population of Bermudian wrasses to become locally extinct, without replenishment. In an attempt to estimate how long a cohort recruiting in one event would persist, we constructed Table 4 . which projects the time at which cohort abundance would drop to low levels under a range of constant daily mortality rates. The mortality rates used in Table 4 bracket the range of mortality rates reported for Thalassoma bifasciatum (Warner 1984, Victor 1986c). Because mortality rates appear to be 
Table 4. Lifespan estimates for a range of daily mortality rates, with time required to reduce the cohort to $10 \%, 1 \%$ and $0.1 \%$ of its initial abundance. Daily mortality rates are based on ranges of values estimated for Thalassoma bifasciatum (Warner 1984, Victor 1986c) and 11 Great Barrier Reef wrasses (Eckert 1987)

\begin{tabular}{|c|c|c|c|c|}
\hline $\begin{array}{l}\text { Daily } \\
\text { mortality }\left(q_{\mathrm{d}}\right)\end{array}$ & $\begin{array}{l}\text { Annual survivor- } \\
\operatorname{ship}\left(I_{x}\right)\end{array}$ & \multicolumn{3}{|c|}{$\begin{array}{l}\text { Time (yr) required } \\
\text { to reduce cohort to: }\end{array}$} \\
\hline 0.0005 & 0.83 & 13 & 25 & 38 \\
\hline 0.001 & 0.69 & 6.3 & 13 & 19 \\
\hline 0.002 & 0.48 & 3.2 & 6.3 & 9.4 \\
\hline 0.003 & 0.33 & 2.1 & 4.2 & 6.3 \\
\hline 0.004 & 0.23 & 1.6 & 3.1 & 4.7 \\
\hline 0.005 & 0.16 & 1.3 & 2.5 & 3.8 \\
\hline 0.006 & 0.11 & 1.0 & 2.1 & 3.1 \\
\hline 0.007 & 0.077 & 0.90 & 1.8 & 2.7 \\
\hline 0.008 & 0.053 & 0.78 & 1.6 & 2.4 \\
\hline 0.009 & 0.037 & 0.70 & 1.4 & 2.1 \\
\hline 0.01 & 0.026 & 0.63 & 1.2 & 1.9 \\
\hline
\end{tabular}

relatively high for a short period following settlement, the analysis should be viewed as pertaining to a period beginning after the first few weeks on the reef. A cohort is predicted to decrease in abundance by 2 or 3 orders of magnitude within a decade. Even with the surprisingly low mortality rates reported for the Great Barrier Reef wrasses (Eckert 1987), a cohort will be reduced 2 orders of magnitude within 25 yr. Comparing these lifespan estimates with the recurrence interval in Table 3 reveals that the time between recruitment events (at the average PLD) should exceed lifespan for at least 3 species (Halichoeres bivittatus, $H$. garnoti, and H. radiatus). For example, with a recurrence interval of $29 \mathrm{yr}$, Bermuda populations of $H$. bivittatus will be maintained above $0.1 \%$ of the abundance at recruitment only if daily mortality rates are at or below the extremely low value of 0.0005 .

Perhaps these species are abundant in Bermuda only sporadically, following a major recruitment event, and remain present only as a single or limited number of recruitment cohorts. However, all the species studied here are predictably common on Bermuda reefs, and represented by a broad size range inconsistent with multi-year periods of recruitment failure (B. Luckhurst, Division of Fisheries, Bermuda, pers. comm; authors' pers. obs.j. Moreover, the analysis of settlement dates indicated that the individuals we sampled had recruited over time, rather than in a single pulse; because our sampling interval was limited, and our sampling approach targeted small, easily captured individuals, most of our specimens had settled to the reef in a recent $4 \mathrm{wk}$ period, but there was no indication of a single dramatic settlement event within this interval. While it is clear that more study is needed on local recruitment dynamics, the characteristics of these populations do not seem to be consistent with a scenario of infrequent recruitment of larvae that have been imported from distant source populations.

The comparison of the Bermuda PLD data with PLDs from other samples also indicates that long-distance dispersal to Bermuda was unlikely, at least for this sample of recruits. The transport time results show that it is not possible for larvae to reach Bermuda from Cape Hatteras within a typical larval duration of a few weeks. Some wrasses (e.g. Thaiassoma bifasciatum: Victor 1986a) have the ability to delay metamorphosis if they are not close to substrate suitable for settlement by the time the larva is competent to settle. One may deduce that delayed metamorphosis is more likely in cases where larvae have to travel a greater distance, and where this transport takes a longer time, to reach adult habitat (Cowen 1985, 1991). Therefore, the Bermuda PLDs should be long if those larvae were transported from Cape Hatteras or the Caribbean, relative to PLDs of larvae that settled in areas where source populations are located nearby. The PLD estimates of Victor (1986a; Table 2) were taken from specimens collected at the San Blas archipelago, off the Caribbean coast of Panama. Coral reef habitats are common along the Caribbean Latin American coast, and the transport of larvae to the San Blas from elsewhere should occur more commonly and more rapidly than long-distance transport to Bermuda. Nonetheless, in 4 out of the 6 comparisons (Table 2), Bermuda PLDs were the same as or shorter than Panama PLDs. The mean difference in the remaining 2 species was 5 or $6 \mathrm{~d}$. Clearly, the prediction that Bermuda PLDs would be longer than the San Blas PLDs is not supported, furnishing another line of evidence for rejection of the long-distance dispersal hypothesis. It should be noted that the comparison of PLDs cannot be used as a test of alternative hypotheses, per se. While the similarity of PLDs along with the transport time estimates is strong evidence against transport from elsewhere, the alternative result of longer PLDs for Bermuda fish would not have militated against local retention, given that some of the longest larval durations for labrids occur among the Hawaiian endemics (Victor 1986a).

Thus, with the possible exception of Thalassoma bifasciatum, these analyses indicate that populations of labroids common to Bermuda are mostly selfseeding. Aside from the high-quality age record, labroids were chosen in this study for their dispersive ability. Long-distance dispersal may be even more characteristic of a few other reef fish species, such as those that metamorphose pelagically, or those that have a specialized larval phase for dispersal (Richards \& Lindeman 1987, Leis 1991). These may reach Bermuda from other sources more regularly. But pelagic 
breeders with shorter PLDs (e.g. grunts; Brothers \& McFarland 1981), as well as the demersal spawners producing larvae that can swim from the moment of hatching (e.g. damselfish; Leis 1991), are even more likely to be locally retained than the wrasses. This conclusion should apply to many invertebrates as well. Most larval durations for invertebrates are in the same range as the labroids reported here. For example, the larval duration for the queen conch Strombus gigas ranges from 12 to 35 d (Ballantine \& Appeldoorn 1983, Davis \& Hesse 1983)

While our results indicate that long-distance transport for these reef fishes is infrequent, they do not suggest that Bermuda is so remote from potential source populations to the west and south that genetic isolation will occur. If the recruitment events depicted by these 'best-case scenario' models occur at the predicted frequencies, there is a fairly good rate of gene flow from the Caribbean. In other words, Bermuda is rather isolated in ecological time, but may not be in evolutionary time, from the source populations in the Caribbean. Whether the rate of long-distance dispersal is sufficient to maintain genetic identity of the Bermuda and Caribbean populations is not yet clear. The limited data on population genetic structure of Bermuda reef dwellers suggests that the rate of gene flow may be dependent on larval duration as has been shown elsewhere (Waples 1987). Out of 7 polymorphic loci of Strombus gigas analyzed by Mitton et al. (1989), 1 locus had a significantly different allelic makeup in Bermuda, compared to Caribbean collection sites. In contrast, a recent allozyme analysis of the spiny lobster Panulirus argus found that Bermuda residents could not be distinguished from mainland and Caribbean samples (Hately \& Sleeter 1993). The lobster has a longer larval duration, up to 13 mo (Farmer et al. 1990). This 2-point comparison supports an implication of our results, that there should be copious gene flow to Bermuda in a species that spends a year in the plankton, while flow should be relatively restricted in species with more typical larval durations of a month or less. The degree of isolation at Bermuda is of particular interest, because Caribbean populations of reef dwellers appear to be essentially homogenous (Mitton et al. 1989, Lacson 1992, Hately \& Sleeter 1993). Clearly, there is a pressing need to analyze samples from Bermuda, and other isolated sites with tropical western Atlantic species (e.g. Ascension Island: Lubbock 1980).

Considerable work remains to be done. Information on the dynamics of recruitment of reef fishes and invertebrates at Bermuda would be especially valuable. With respect to the flows that have been identified as possible modes of transport, it would be useful to know whether a recruitment pulse is coincident with the arrival of a CCR or an outbreak in the area. With respect to the dynamics of a self-seeding population, long-term study of the relationship between the abundance of breeding adults on the reef and subsequent recruitment is needed. The isolation of Bermuda populations may reduce their resilience to overfishing or other perturbations, as suggested by Mitton et al. (1989; see also Lutjeharms \& Heydorn 1981a, b).

\section{Evaluation of transport models and comparison with drifter data}

The transport models yielded distinct differences in the frequency of long-distance transport (Fig. 3A, B, C, Table 3). Cold-core rings, with their slow and erratic wanderings, prove to be an ineffective mode of transportation. Outbreaks may move water more quickly to Bermuda. Unfortunately, relatively little is known about these water masses. While they superficially resemble warm outbreaks described by Cornillon et al. (1986; see also Vukovich \& Crissman 1978, Pratt et al. 1991), many of the outbreaks in the SST charts we used for our data are more extensive and more persistent. In our models, we attempted to represent 2 different behaviors of these masses. The fixed position model incorporated an estimate of the internal circulation of the outbreak, relative to the water in the Sargasso Sea, while the southern margin model incorporated translations of the water mass by tracking a specific feature. Outbreak translation is usually tied to movement of an associated cold-core ring; nonetheless, outbreak translation provides more rapid transit to Bermuda than ring translation, because portions of outbreak water can be suddenly captured by another ring to the south

Assumptions that tend to bias the results in favor of long-distance transport were built into the models. The source populations were assumed to be located off Cape Hatteras, which is likely to be well north of the reproductive populations for many of these species. Minimal time $(1 \mathrm{~d})$ was provided for outbreak of propagules in the GS. The fastest flows observed for the GS were used to estimate travel times, with no consideration given to any deceleration of the GS once it leaves Cape Hatteras. At the Bermuda end, we assumed that larvae needed no time to find habitat and settle out. It is unclear whether GS water captured in cold-core rings or outbreaks might bathe Bermuda's reefs: the relatively shallow bathymetry of the slope around the atoll tends to repel approaching rings (A. Michaels, Bermuda Biological Station, pers. comm.). Finally, we assumed that rings and outbreaks reach Bermuda 4 times a year. While there are data to support this estimate of visitation frequency (Hogg et al. 
1978; authors' pers. obs.), it is likely to be an overestimate of the frequency with which these events could bring recruiting larvae, because the recruitment season in Bermuda is limited to the warmer months (May to September; B. Luckhurst pers. comm.), and the production of larvae in the shallow waters off the mainland USA is likely to be seasonal as well.

These models of larval transport times should not be construed as attempts to realistically represent the circulation of the GS/Sargasso Sea system. The models reflect only the 2-dimensional behavior of water masses seen in sea-surface temperature charts of the northern Sargasso Sea. There was no attempt to accommodate forces and processes such as friction, mixing, or wind. Moreover, as earlier practitioners have stressed (Auer 1987), use of sea-surface temperature charts to track the behavior of cold-core rings and associated outbreaks has not been properly validated. The fixed position model is especially unrealistic in the sense that the chances of outbreaks remaining stationary for such periods are extremely slim. Nonetheless, the transport distances represented by the outbreak dimensions incorporated into this model should be reasonable.

Another simplification of the models that should be pointed out is that there was no attempt to include estimates of larval abundance. Use of the recurrence interval as the final arbiter of the likelihood of recruitment implicitly assumes that larval concentrations in each water mass will be sufficient to repopulate the Bermuda reefs. However, losses of larvae may be so great that only a small number of propagules manage to make the trip to Bermuda from source populations elsewhere. An approach to modelling larval losses due to mortality, diffusion, and advection (Hill 1991) has shown that the rate of advection can have a major impact on the rate of successful recruitment to a site (whether recruitment is to the same site as spawning. or at some distance from it). Hill (1991) also makes the point that a highly productive (i.e. fecund) source population will contribute few or no individuals to a recruitment site if the advection rate is such that the larvae fail to reach the site or are swept past before they become competent to settle. Explicit modelling of larval loss rates may be useful in future attempts to resolve whether recruits are imported from elsewhere or are self-seeding. Presently, there is virtually no information on the concentrations of reef fish larvae in the Gulf Stream, outbreaks in the Sargasso Sea, or around Bermuda, so it would be impossible to realistically parameterize such a model.

Despite the limitations of the models, we doubt that the likelihood of long-distance transport has been underestimated, especially given the biases discussed above. Furthermore, observations of drifter transport support the contention that our estimates of transport time are accurate, or err on the short side.

Several conclusions may be drawn from the drifter data (Fig. 5). Downstream transport speeds in the GS will certainly be slower than the $160 \mathrm{~cm} \mathrm{~s}^{-1}$ speed used in the models, even if transport occurs in the fastest part of the GS, along the GSLSE. On the other hand, these drifters moved more rapidly in the Sargasso Sea than predicted by our models (average of $1.0 \mathrm{~cm} \mathrm{~s}^{-1}$ in the CCR model, $29 \mathrm{~cm} \mathrm{~s}^{-1}$ in the fixed position model, and $18 \mathrm{~cm} \mathrm{~s}^{-1}$ in the southern margin model). Other estimates of speeds of advection in detrained GS water are in better agreement with our models: Cornillon et al. (1986) report drifter speeds of 8 to $33 \mathrm{~cm} \mathrm{~s}^{-1}$. Another implication of the drifter results is that propagules entering the GS from the landward side may be transported quite some distance east before they are detrained into the Sargasso. This would reduce their chances of being advected to Bermuda within a reef fish's PLD to almost nil.

\section{Approaches to the study of local retention}

Several researchers have approached the retention hypothesis more directly, by focusing on local flow around islands and attempting to map larval distributions on these flows. The earliest studies were those of Lobel \& Robinson (1986) in the Hawaiian Islands. A set of drifters they deployed indicated some degree of return flow, but their larval survey methods were not adequate to demonstrate that the water was carrying appreciable numbers of reef fish larvae. More recently, Boehlert et al. (1992) found high nearshore concentrations of reef-fish larvae around Johnston Atoll. The larvae were identifiable to families that spawn demersally, which seems to be typical of nearshore larval assemblages (Leis \& Miller 1976, Boehlert \& Mundy 1993). Boehlert et al. (1992) utilized XBT and CTD data to study the flow field around Johnston Atoll, and found some evidence for gyres in the island wake, such as might be generated in a von Karman vortex street. More detail of the flow is needed to confirm that such gyres function to retain and return larvae to the reefs. Currently, a detailed study is underway at Barbados, combining information on island-scale flow with larval distributions and recruitment patterns (Cowen \& Castro in press). A topographically steered flow has been identified that returns water to the island, and within this flow reef fish larvae are especially abundant (several orders of magnitude above background). In this case, the mechanism for local retention is particularly clear, although it remains uncertain how temporally stable this flow is or how it might apply to other locations. 
The present study, which indirectly supports the concept of larval retention by rejecting its alternative, does not offer any insight into how such retention might occur. Comprehensive analyses will ultimately have to draw from studies on larval behaviors and distribution patterns, the duration of larval periods, and population genetic structure, combined with largescale, meso-scale, and island-scale circulation patterns. Small, isolated sites, such as Bermuda, Barbados, and Johnston Atoll, are good places to initiate larval retention studies. The small scale of these systems maximizes the feasibility of concurrently mapping larvae and circulation patterns. By arguments similar to those laid out here, it can be shown that retention is likely at other isolated islands. Flows which concentrate larvae at such sites are good candidates for retention mechanisms. Once the effectiveness of retention mechanisms has been confirmed for isolated sites, their applicability to other marine environments (e.g. archipelagos, continental reefs) will be of particular interest (Cowen \& Castro in press).

Acknowledgements. The sharp nets and fast eyes of J. Hare and S. Sponaugle enabled us to collect fish in Bermuda. Lodging and logistics in Bermuda were ably arranged by the staff of the Bermuda Biological Station for Research. B. Luckhurst assisted us from beginning to end of the research effort. Special thanks to S. S. Ross for otolith interpretation, E.A.S Schultz for discussions on larval behavior and LVAO Travel. P. Cornillon, N. Hogg, K. Lwiza, and the students of MAR 502 provided expertise in matters physical. S. Auer of the National Weather Service, and J. Clark of NOAA, helped us interpret the satellite imagery; P. Dragos of Batelle, Inc., assisted us with drifter data. P. Richardson kindly sent us other helpful information on Sargasso Sea circulation. The honest reviews of J. Hare, K. Lwiza, S. Sponaugle and 3 anonymous referees contributed improvements to the manuscript. The authors were supported by NSF grants OCE 8911120 to R.K.C. and M. J. Bowman, and 9217025 to D. O. Conover and E.T.S. This is contribution 955 of the Marine Science Research Center.

\section{LITERATURE CITED}

Auer, S. J. (1987). Five-year climatological survey of the Gulf Stream system and its associated rings. J. geophys. Res. 92: $11709-11726$

Bakun, A. (1986). Local retention of planktonic early life stages in tropical reef bank demersal systems: the role of verticaly-structured hydrodynamic processes. In: Pauly, D., Yanez-Arancibia, A. (eds.) IOC/FAO Workshop on Recruitment in Tropical Coastal Demersal Communities, IOC Workshop Report 44. UNESCO, Paris, p. 15-32

Ballantine, D. L., Appeldoorn, R. S. (1983). Queen conch culture and future prospects in Puerto Rico. Proc. Gulf Caribb. Fish. Inst. 35: 57-63

Black, K. P.. Moran, P. J., Hammond, L. S. (1991). Numerical models show coral reefs can be self-seeding. Mar. Ecol. Prog. Ser. 74: 1-11

Boden, B. P. (1952). Natural conservation of insular plankton. Nature 169: 697-699
Boehlert, G. W., Mundy, B. C. (1993). Ichthyoplankton assemblages at seamounts and oceanic islands. Bull. mar. Sci 53: $336-361$

Boehlert, G. W., Watson, W., Sun, L. C. (1992). Horizontal and vertical distributions of larval fishes around an isolated oceanic island in the tropical Pacific. Deep Sea Res. 29: $439-466$

Brothers, E. B., McFarland, W. N. (1981). Correlations between otolith microstructure, growth, and life history transitions in newly recruited French grunts [Haemulon flavolineatum (Desmarest), Haemulidae). Rapp. P.-v. Réun. Cons. int. Explor. Mer 178: 369-374

Campana, S. E., Neilson, J. D. (1985). Microstructure of fish otoliths. Can. J. Fish. Aquat. Sci. 42: 1014-1032

Cornillon, P., Evans, D., Large, W. (1986). Warm outbreaks of the Gulf Stream into the Sargasso Sea. J. geophys. Res. 91. 6583-6596

Cowen, R. K. (1985). Large scale pattern of recruitment by the labrid, Semicossyphus pulcher: causes and implications. J mar. Res. 43: 719-742

Cowen, R. K. (1991). Variation in the planktonic larval duration of the temperate wrasse Semicossyphus pulcher. Mar. Ecol. Prog. Ser. 69: 9-15

Cowen, R. K. Castro, L. R. (in press). Relation of coral reef fish distribution to island scale circulation around Barbados, West Indies. Bull. mar. Sci.

Davis, M., Hesse, C. (1983). Third world level conch mariculture in the Turks and Caicos Islands. Proc. Gulf Caribb. Fish. Inst. 35: 73-82

Eckert, G. J. (1987). Estimates of adult and juvenile mortality for labrid fishes at One Tree Reef, Great Barrier Reef. Mar Biol. 95: 167-171

EPA (Environmental Protection Agency) (1993). Satellitetracked surface-layed drifters released at the 106-mile site. Report submitted to the U.S. EPA under Contract 68 C8-0105. Work Assignment 3-41. Battelle Ocean Sciences, Duxburg, MA

Farmer, M. W., Ward, J., Luckhurst, B. E. (1990). Development of spiny lobster (Panulirus argus) larvae in waters near Bermuda. Proc. Gulf Caribb. Fish. Inst. 39: 289-301

Farmer, M. W., Berg, C. J. Jr (1990). Circulation around islands, gene flow, and fisheries management. Proc. Gulf Caribb. Fish. Inst. 39: 318-330

Gill, A. E. (1982). Atmosphere-ocean dynamics. Int. Geophys Ser. 30. Academic Press, New York

Grimes, C. B., Manooch, C. S., Huntsman, G. R. (1982). Reef and rock outcropping fishes of the outer continental shelf of North Carolina and South Carolina, and ecological notes on the red porgy and vermilion snapper. Bull. mar Sci. 32: $277-289$

Hamner, W. M., Hauri, I. R. (1981). Effects of island mass: water flow and plankton pattern around a reef in the Great Barrier Reef lagoon, Australia. Limnol. Oceanogr 26: $1084-1102$

Hately, J. G., Sleeter, T D. (1993). A biochemical genetic investigation of spiny lobster (Panulirus argus) stock replenishment in Bermuda. Bull. mar. Sci. 52: 993-1006

Hill, A. E. (1991). Advection-diffusion-mortality solutions for investigating pelagic larval dispersal. Mar. Ecol. Prog. Ser. 70: $117-128$

Hogg, N. G., Katz, E. J., Sanford, T. B. (1978). Eddies, islands, and mixing. J. geophys. Res. 83: 2921-2938

Johannes, R. E. (1978). Reproductive strategies of coastal marine fishes in the tropics. Environ. Biol. Fish. 3: 65-84

Kingsford, M. J. (1990). Linear oceanographic features: a focus for research on recruitment processes. Aust. J. Ecol. 15: $391-401$ 
Kingsford, M. J., Wolanski, E., Choat, J. H. (1991). Influence of tidally induced fronts and Languir circulations on distribution and movements of presettlement fishes around a coral reef. Mar. Biol. 109: 167-180

Kobayashi, D. R. (1989). Fine-scale distribution of larval fishes: patterns and processes adjacent to coral reefs in Kaneohe Bay, Hawaii. Mar. Biol. 100: 285-293

Lacson, J M. (1992). Minimal genetic variation among samples of six species of coral reef fishes collected at La Parguera, Puerto Rico, and Discovery Bay, Jamaica. Mar. Biol. 112: 327-331

Lai, D. Y., Richardson, P. L. (1977). Distribution and movement of Gulf Stream rings. J. phys. Oceanogr. 7: 670-683

Leaman, K. D., Johns, E., Rossby, T (1989). The average distribution of volume transport and potential vorticity with temperature at three sections across the Gulf Stream. J. phys. Oceanogr 19:36-51

Leis, J. M. (1982). Nearshore distributional gradients of larval fish (15 taxa) and planktonic crustaceans (6 taxa) in Hawaii. Mar. Biol. 72: 89-97

Leis, J. M. (1986). Vertical and horizontal distribution of fish larvae near coral reefs at Lizard Island, Great Barrier Reef. Mar. Biol. 90: 505-51.6

Leis, J. M. (1991). The pelagic stage of reef fishes. In: Sale, P. F. (ed.) The ecology of fishes on coral reefs. Academic Press, New York, p. 183-230

Leis, J. M. (1993). Larval fish assemblages near Indo-Pacific coral reefs. Bull. mar. Sci. 53: 362-392

Leis, J. M., Miller, J. M. (1976). Offshore distributional patterns of Hawaiian fish larvae. Mar. Biol. 36: 359-367

Lindquist, D. G., Pietrafesa, L. J. (1989). Current vortices and fish aggregations: the current field and associated fishes around a tugboat wreck in Onslow Bay, North Carolina. Bull. mar. Sci. 44: 533-544

Lobel, P. S., Robinson, A. R. (1986). Transport and entrapment of fish larvae by ocean mesoscale eddies and currents in Hawailan waters. Deep Sea Res. 33: 483-500

Lubbock, R. (1980). The shore fishes of Ascension Island. J. Fish Biol. 17: 283-303

Lutjeharms, J. R. E., Heydorn, A. E. F. (1981a). The rocklobster Jasus tristani on Vema Seamount: drifting buoys suggest a possible recruiting mechanism. Deep Sea Res. 28A: $631-636$

Lutjeharms, J. R. E., Heydorn, A. E. F. (1981b). Recruitment of rock lobster on Vema Seamount from the islands of Tristan da Cuhna. Deep Sea Res. 28A: 1237

Manning, J. P., Watts, D. R. (1989). Temperature and velocity structure of the Gulf Stream northeast of Cape Hatteras: modes of variability. J. geophys. Res. 94: 4879-4890

Miller, G. C., Richards, W. J. (1979). Reef fish habitat, faunal assemblages, and factors determining distributions in the South Atlantic Bight. Proc. Gulf Caribb. Fish. Inst. 32: $114-130$

Mitton, J. B., Berg, C. J. Jr, Orr, K. S. (1989). Population structure, larval dispersal, and gene flow in the queen conch, Strombus gigas, of the Caribbean. Biol. Bull. 177: 356-362

Parker, R. O. Jr (1990). Tagging studies and diver observations of fish populations on live-bottom reefs of the U.S. southeastern coast. Bull. mar. Sci. 46: 749-760

Pillai, C. S. G., Mohan, M., Kunhikoya, K. K. (1983). On an unusual massive recruitment of the reef fish Ctenochaetes strigosus (Bennet) (Perciformes: Acanthuridae) to the Minicoy Atoll and its significance. Indian J Fish. 30: $261-268$

Pond, S., Pickard, G. L. (1983). Introductory physical oceanography, 2nd edn. Pergamon Press, Oxford
Powles, H. (1975). Abundance, seasonality, distribution and aspects of the ecology of some larval fishes off Barbados. Ph.D. dissertation, McGill University, Montreal

Pratt, L. J., Earles, J., Cornillon, P., Cayula, J.-F. (1991). The nonlinear behavior of varicose disturbances in a simple model of the Gulf Stream. Deep Sea Res. 38: S591-S622

Richards, W. J., Lindeman, K. C. (1987). Recruitment dynamics of reef fishes: Planktoric processes, settlement and demersal ecologies, and fisheries analysis. Bull. mar Sci. 41: 392-410

Richardson, P. L., Wheat, J. J., Bennett, D. (1979). Freedrifting buoy trajectories in the Gulf Stream system. Woods Hole Oceanographic Institution Technical Report WHOI-79-4, Woods Hole, MA

Richardson, P. L. (1980). Gulf Stream ring trajectories. J. phys. Oceanogr. 10: 90-104

Richardson, P. L. (1983). Gulf Stream rings. In: Robinson, A. R. (ed.) Eddies in marine science. Springer-Verlag, Berlin, p. $19-45$

Ring Group. (1981). Gulf Stream cold-core rings: their physics, chemistry, and biology. Science 212: 1091-1100

Rosenblatt, R. H., Waples, R. S. (1986). A genetic comparison of allopatric populations of shore fish species from the eastern and central Pacific Ocean: dispersal or vicariance? Copeia 1986: $275-284$

Sale, P. F. (1970). Distribution of larval Acanthuridae off Hawaii. Copeia 1970: 765-766

Scheltema, R. S. (1986). On dispersal and planktonic larvae of benthic invertebrates: an eclectic overview and summary of problems. Bull. mar. Sci. 39: 290-322

Stevenson, D. K., Campana, S. E. (eds.) (1992). Otolith microstructure examination and analysis. Can. Spec. Publ Fish. Aquat. Sci. 117

Tee-Van, J. (1930). How Bermuda acquired its shore fishes Bull. N.Y. Zool. Soc. 33:67-72

Thresher, R. E., Brothers, E. B. (1985). Reproductive ecology and biogeography of Indo-West Pacific angelfishes (Pisces: Pomacanthidae). Evolution 39: 878-887

Victor, B. C. (1986a). Duration of the planktonic larval stage of one hundred species of Pacific and Atlantic wrasses (family Labridae). Mar. Biol. 90: 317-326

Victor, B. C. (1986b). Delayed metamorphosis with reduced larval growth in a coral reef fish (Thalassoma bifasciatum). Can. J. Fish. Aquat. Sci. 43: 1208-1213

Victor, B. C. (1986c). Larval settlement and juvenile mortality in a recruitment-limited coral reef fish population. Ecol. Monogr. 56: 145-160

Vukovich, F. M., Crissman, B. W. (1978). Observations of the intrusion of a narrow warm tongue into the Sargasso Sea using satellite and in situ data. J. geophys. Res. 83 $1929-1934$

Waples, R. S. (1987). A multispecies approach to the analysis of gene flow in marine shore fishes. Evolution 41 $385-400$

Warner, R. R. (1984). Deferred reproduction as a response to sexual selection in a coral reef fish: a test of the life historical consequences. Evolution 38: 148-162

Warner, R. R., Chesson, P. L. (1985). Coexistence mediated by recruitment fluctuations: a field guide to the storage effect. Am. Nat. 125: 769-787

Watts, D. R. (1983). Gulf Stream variability. In: Robinson, A. R. (ed.) Eddies in marine science. Springer-Verlag, Berlin, p. $114-144$

Wellington, G. M., Victor, B. C. (1989). Planktonic larval duration of one hundred species of Pacific and Atlantic damselfishes (Pornacentridae). Mar. Biol. 101: 557-567 